Published in final edited form as:

Adv Healthc Mater. 2015 August 26; 4(12): 1813-1818. doi:10.1002/adhm.201500307.

\title{
Selenite-releasing bone mineral nanoparticles retard bone tumor growth and improve healthy tissue functions in vivo
}

\section{Dr. Yanhua Wang ${ }^{\dagger}$,}

Advanced Biomaterials and Tissue Engineering Center, Huazhong University of Science and Technology, Wuhan, 430074, China

Department of Biomedical Engineering, Huazhong University of Science and Technology, Wuhan, 430074, China

\section{Hang $\mathrm{HaO}^{\dagger}$,}

Advanced Biomaterials and Tissue Engineering Center, Huazhong University of Science and Technology, Wuhan, 430074, China

Department of Biomedical Engineering, Huazhong University of Science and Technology, Wuhan, 430074, China

Haoming Liu ${ }^{\dagger}$,

Advanced Biomaterials and Tissue Engineering Center, Huazhong University of Science and Technology, Wuhan, 430074, China

Department of Biomedical Engineering, Huazhong University of Science and Technology, Wuhan, 430074, China

\section{Yifan Wang,}

Advanced Biomaterials and Tissue Engineering Center, Huazhong University of Science and Technology, Wuhan, 430074, China

Department of Biomedical Engineering, Huazhong University of Science and Technology, Wuhan, 430074, China

\section{Yan Li [Prof.],}

Department of Oncology, Zhongnan Hospital of Wuhan University, Hubei Key Laboratory of Tumor Biological Behaviors and Hubei Cancer Clinical Study Center, Wuhan, 430074, China

\section{Gaojie Yang,}

Advanced Biomaterials and Tissue Engineering Center, Huazhong University of Science and Technology, Wuhan, 430074, China

Department of Biomedical Engineering, Huazhong University of Science and Technology, Wuhan, 430074, China

\section{Dr. Jun Ma,}

\footnotetext{
Correspondence to: Chuanbin Mao, cbmao@ou. edu; Shengmin Zhang, smzhang@mail . hust .edu.cn.

$\dagger$ Equal contributions

Supporting Information

Supporting Information is available from the Wiley Online Library or from the author.
} 
Advanced Biomaterials and Tissue Engineering Center, Huazhong University of Science and Technology, Wuhan, 430074, China

Department of Biomedical Engineering, Huazhong University of Science and Technology, Wuhan, 430074, China

Chuanbin Mao [Prof.], and

Department of Chemistry and Biochemistry, Stephenson Life Sciences Research Center, University of Oklahoma, Norman, Oklahoma 73019, USA

\section{Shengmin Zhang [Prof.]}

Advanced Biomaterials and Tissue Engineering Center, Huazhong University of Science and Technology, Wuhan, 430074, China

Department of Biomedical Engineering, Huazhong University of Science and Technology, Wuhan, 430074, China

Chuanbin Mao: cbmao@ou.edu; Shengmin Zhang: smzhang@mail.hust.edu.cn

\section{Keywords}

nanoparticles; hydroxyapatite; selenite; osteosarcoma; bone mineral; selenium; bone

Osteosarcoma is a primary solid neoplasm, about $20 \%$ of which is derived from malignant cancerous bone tissue. It usually grows on the metaphysis of long bone, and often metastasizes to lungs. Unfortunately, it is prevalent amongst teenagers and has the highest morbidity. Although the current chemotherapy significantly improves patient's quality of life, $40-50 \%$ of the patients die due to pulmonary metastasis. ${ }^{[1]}$ After a decade's effort, osteosarcoma was still treated with limited success. Consequently, researchers have turned to biomaterials with antitumor effects. ${ }^{[2,3]}$ Ideally, such biomaterials should not only fill the bone defects caused by the tumor surgery, but also inhibit tumor recurrence. Hence, this work aims to integrate the two functions into one biomaterial.

Hydroxyapatite (HA) nanoparticles (HANs) are the main inorganic mineral in bone and tooth enamel. ${ }^{[4]}$ Recently doping certain trace element into the HA structure has attracted much attention in order to modify HA functions. Various trace elements, such as magnesium, ${ }^{[5]}$ strontium, ${ }^{[6]}$ silicon, ${ }^{[7]}$ and zinc, ${ }^{[8]}$ have been incorporated into the HA crystals for the purpose of osteogenesis stimulation and inflammatory suppression. However, selenium doping has been seriously ignored although it is a nutritional trace element, which has been intimately associated with many health problems, such as arthropathy and cardiomyopathy, thyroid function, immune function and reproductive function. ${ }^{\left[{ }^{9-11]}\right.}$ It is known that sodium selenite, a typical supplementation form of selenium, can inhibit the proliferation of various kinds of cancer cells via its apoptosis-inducing effect. ${ }^{[12-14]}$ In addition, nanomaterials have shown great potential in treating cancer. ${ }^{[15-19]}$ Therefore, we propose that the incorporation of selenite ions into HA crystals might be an innovative idea for treating osteosarcoma. Herein, for the first time, we proposed to investigate the HANs doped with selenite ions (HANSe) for in vivo targeted treatment of osteosarcoma of human origin. Firstly, an in situ nude mouse model of osteosarcoma was constructed. Then the 
efficacy of the HANSe materials in treating osteosarcoma was systematically investigated (Scheme 1).

HAN, HANSe3, and HANSe10 nanoparticles were prepared with selenite ions doped at the $\mathrm{Se} / \mathrm{P}$ mass ratio of $0 \%, 3 \%$ and $10 \%$, respectively, following our reported protocol. ${ }^{[20]}$ The nanoparticles were found to be needle-like (Scheme 1b) and the typical length of the nanoparticles ranged from 300 to $800 \mathrm{~nm}$ (Scheme 1b and Figure S1). The release profiles of selenite ions from the HANSe powders in phosphate buffered saline (PBS) solution (Figure 1a) showed that HANSe 3 and HANSe 10 presented different release behaviors. The total amount of selenite released from HANSe 3 and HANSe 10 could reach $89.72 \%$ and $30.64 \%$, respectively. Compared with HANSe10, HANSe3 exhibited sustainable release of selenite ions in PBS solution, which might influence their antitumor effect.

After HANSe materials were intratumorally injected into the osteosarcoma, HANSe3 exhibited the least tumor volume among all groups. Before treatment, the tumor volume was almost the same for all groups. But after treatment for 30 days, there was a significant difference in tumor size between different groups. HANSe3 group showed the slowest rate of tumor growth $(p<0.05)$. The tumor volume of the HANSe3 group was increased from $(140.81 \pm 55.25) \mathrm{mm}^{3}$ to $(1496.82 \pm 878.69) \mathrm{mm}^{3}$. In contrast, the tumor volume of the HANSe10 group was increased from $(194.20 \pm 55.04) \mathrm{mm}^{3}$ to $(3329.82 \pm 762.75) \mathrm{mm}^{3}$. There was no significant difference in tumor volume among control, HAN and HANSe10 group $(p>0.05)$. Similar results were noted in the images of the tumors (Figure 1c). The tumors in HAN and HANSe10 group were larger than those in HANSe3 group, and some white powder materials were evident on the surface of the tumors in the HAN and HANSe10 groups. The HANSe3 group not only showed the greatest retardation in tumor volume but also the lowest amount of the residual materials on the surface of the tumors, demonstrating its better biodegradability. Hydroxyapatite is of the lowest solubility in physiological medium among calcium phosphate materials. ${ }^{[26]}$ These results, along with those obtained from selenium release profiles in PBS solution (Figure 1), indicated that HANSe3 materials could be degraded in the tumor tissue and then release selenite ions, which further inhibited tumor growth. Indeed, selenite ions could inhibit cancer cell growth by inducing apoptosis. ${ }^{[27-29]}$

All animals survived until the endpoint of the experiment without showing death, infection, and edema. Although different levels of toxicity were noted in all groups, HANSe3 showed lower systemic toxicity than the other three groups, as reflected by the blood test data (Table S1). There was a slight decrease in the number of white blood cells (WBC) in HAN and HANSe3 group. However, an increase in WBC number was observed in HANSe10 group, implying that HAN and HANSe 3 could not induce inflammation and HANSe 3 exhibited good blood compatibility. The red blood cells (RBC), hemoglobin (HGB) and hematocrit (HCT) indexes decreased after treatment with HAN, HANSe3 and HANSe10. Compared to the control, HAN and HANSe10 group, HANSe3 also exhibited a notable decrease in mean corpuscular volume (MCV), mean corpuscular hemoglobin (MCH). In addition, mean corpuscular hemoglobin concentration (MCHC) was higher in HAN and HANSe10 group than in HANSe3 group. However, there was no statistical difference in red blood cell volume distribution width (RDW) and red blood cell volume distribution width-standard deviation 
(RDW-SD) among all groups. All except the control group caused decreases in platelet (PLT) and platelet hematocrit (PCT) following treatment. Moreover, HANSe3 treatment also resulted in a decrease in mean platelet volume (MPV), platelet volume distribution width (PDW) and platelet-large cell ratio (P-LCR). All of these results indicate that HANSe3 material was not toxic to the circulation system.

Biochemical parameters of blood were also evaluated in the study (Figure S2). Initially, the 4 groups showed no significant differences in the levels of alanine aminotransferases (ALT), blood urea nitrogen (BUN) and alkaline phosphatase (ALP) $(p>0.05)$. However after treatment, the aspartate transaminase (AST) and creatinine (Cr) level in HANSe3 group decreased dramatically compared to HANSe10 $(p<0.05)$, while the lactic dehydrogenase (LDH) level of these two groups was unchanged. There was also a statistically significant difference in LDH level between HAN group and the HANSe3 group ( $p=0.0042)$. These results showed a clear improvement in the blood levels of ALT, AST, BUN, Cr and LDH 30 days post HANSe3-treatment. This result suggested that HANSe 3 could decrease the systemic toxicity caused by the malignant behavior of tumor cells and also enhance the functions of the liver, kidney and heart. The malignancy of osteosarcoma cells was very high; they grew fast and produced a lot of wastes owing to the high metabolic rate, increasing the burden of liver and kidney. Since the HANSe3 released more selenite ions (Figure 1a), the antioxidant properties of the released selenite ions could have indirectly protected the liver, kidney and heart function. ${ }^{[25-27]}$

Osteosarcoma often metastasizes to lungs via the blood stream. To determine whether there was metastasis to main organs in the mice after treatment, autopsy was conducted at the endpoint of the experiment. In the HANSe treatment groups, no evidence of matasitasis to lungs was observed as the histological morphology of the lung tissues in these groups was similar to that of the normal lung tissues (Figure S3). However, the control group exhibited visible liver metastasis (Figure 2a). Such metastasis was also evident in lungs as hematoxylin-eosin (H\&E) staining exposed the existence of two metastatic osteosarcomas in the pulmonary tissue and the two tumors were separated by pulmonary alveoli (Figure $2 b$ ). These metastatic tumor cells were fusiformic and polymorphic with a deep-dyed, big nucleus that showed a typical mitotic phase. Analysis of the liver tissue demonstrated another form of damage, as featured by hepatocytes necrosis and monocytes infiltration (inflammation reaction) (Figure 2c). Such inflammation responses also occurred in the bone marrow, where enormous giant cells and lymphocytes were scattered within the bone marrow (Figure 2d), which may be induced by osteosarcoma infiltration.

Heart analysis showed that there were structural changes of cardiac muscle (basal unit of the heart), which might hinder or disturb the normal contraction and relaxation processes of the heart (Figure 2e-h). Prominent degenerative changes were well noted in the control, HAN and HANSe10 groups while the cardiac muscle in HANSe3 group exhibited the normal cell integrity with little or no degenerative change. These results confirmed that HANSe 3 could improve the function of the heart by inhibiting cardiac damage of malignant osteosarcoma cells. 
The structural changes in the tumor tissue after 30 days following HANSe 3 treatment were reflected intuitively on the pathological section. As shown in Figure 3, tumor tissue grew actively in the control group with the majority of the tumor cells infringed to the muscular layer. In HAN group, most of the materials were encapsulated by fibrous tissue with active tumor cells residing in the periphery. The tumor cells grew well around the blood vessels, but succumbed to necrosis once far from them. The tumor tissue in HANSe3 group segregated into minor tumor nodules separated by the fibrous tissue. Upon treatment, necrosis was noted in the center with no visible residual materials. In contrast, tumor cells in the HANSe10 group grew fast and invaded the muscular layer. To determine the presence of residual material as a measurement of material biodegradability, von Kossa stain was used to label the calcium and HA in the tissue. ${ }^{[28]}$ It is revealed that the tumors in HAN and HANSe 10 groups were positively stained by the von Kossa staining, but not for the HANSe3 group (Figure 3b). The results show that HAN could not be degraded by the tissue but was aggregated to form granules that were encapsulated by the fiber. HANSe10 was partially degraded by the tumor tissue as evidenced by non-degradable granules in the tissue texture. These direct evidences confirmed that HANSe3 had the best biodegradability.

To investigate the possible molecular mechanism involved in the anti-tumor effect of HANSe, expression of Ki-67 protein and metal matrix proteinase-9 (MMP-9) was evaluated using immunochemical staining following treatment (Figure 3c and 3d). Ki-67 protein is an antigen vital for cell proliferation and positively expressed in G1, S, G2, and M phase of cell cycle. ${ }^{[29,30]}$ It is an important index for malignant tumor development. Tumor cells secret MMP-9 into extracellular matrix, leading to its degradation and thus paving the way to cell invasion and development. ${ }^{[31]}$ The control group was positive for Ki-67 and MMP-9 expression at a rate of $(95.77 \pm 1.76) \%$ and $(61.55 \pm 5.20) \%$, respectively. The HAN group showed a lower level of Ki-67 and MMP-9 with their expression rate being $(86.44 \pm 4.13) \%$ and $(30.88 \pm 2.58) \%$, respectively. For the HANSe3 group, the expression rate of Ki-67 and MMP-9 protein was $(93.11 \pm 2.62) \%$ and $(17.88 \pm 1.88) \%$, respectively, whereas that for the HANSe10 group was $(90.66 \pm 3.26) \%$ and $(14.44 \pm 1.63) \%$. Generally there was no statistical difference in Ki-67 expression ( $p>0.05$ ) between groups, but MMP-9 expression obviously decreased $(p<0.05)$ following treatment, especially in the HANSe group. Thus, our findings suggested that HANSe3 retarded the tumor growth by decreasing MMP-9 expression due to its sustained release of selenite ions. In addition, previous studies showed that a variety of nanoparticles (including HA) can reduce cell migration by increasing intracellular traction stress and enhancing cell adhesion strength.$^{[32]}$ Such effect might also take place in our nanoparticle-treated systems.

Osteosarcomas often penetrate and destroy the cortex of the bone and extend into the surrounding tissues with pulmonary metastases being the most frequent. Surgical resection with neoadjuvant chemotherapy is currently the main treatment approach for osteosarcoma. Surgical removal of the primary tumor is, however, followed by distal recurrence in 80 90\% of the patients. Thus a new approach is needed to inhibit tumor recurrence after the surgical removal of the bone tumors. One approach is to use a biomaterial to fill the bone defect after the surgical removal while inhibiting tumor cells' local recurrence. Our data shown above suggest that HANSe 3 could be such a biomaterial. On one hand, HANSe 3 contains and releases selenite ions that can inhibit cancer progression through their apoptosis-induction 
effect. On the other hand, it resembles the main inorganic component in natural bone and can fill the defect formed after the surgical removal of osteosarcoma. Moreover, Positron emission tomography (PET) imaging showed that HANSe treatment could enhance the glucose metabolism in the tumor cells, which did not conform to the classical metabolism in cancer (Figure S4). In addition, the zeta potentials of the HANSe nanoparticles are lower than $-25 \mathrm{mV}$ (Figure $\mathrm{S} 1$ ), which is required for nanoparticles to be stabilized by electrostatic repulsion. ${ }^{[33]}$ Hence, HANSe3 is a promising nanoparticle system that can be used in treating bone tumors.

In summary, we have developed HANSe3 nanoparticles that can inhibit bone tumor growth and improve healthy organ functions in vivo. Although the mechanism involved was complex, the released selenite ions played a crucial role. These ions could not only suppress tumor growth, but also significantly improve the functions of liver, kidney and heart, leading to enhanced therapy efficacy for osteosarcoma. Such HANSe3 nanoparticles are ideal implants after tumor's wide resections by surgery since they have dual functions-as a scaffold to fill the bone defects caused by the surgery and as a carrier to release drug in a sustained manner to inhibit tumor recurrence. Therefore, our work generates a new strategy for the surgical treatment of osteosarcoma and regeneration of bone defects.

\section{Supplementary Material}

Refer to Web version on PubMed Central for supplementary material.

\section{Acknowledgements}

We would like to sincerely thank Dr. Lihua Shao for the construction of the nude mice model of osteosarcoma of human origin. This work was supported by the National Natural Science Foundation of China (grant no. 31430029, 81071263, 81461148032, 30870624), the National Basic Research Program of China (grant no. 2012CB933601) and the National Key Technology Research and Development Program of China (Grant No.: 2012BAI17B02). CBM would like to thank the financial support from National Institutes of Health (R21 EB015190), National Science Foundation (CMMI-1234957 and DMR-0847758), Department of Defense Peer Reviewed Medical Research Program (W81XWH-12-1-0384), Oklahoma Center for Adult Stem Cell Research (434003) and Oklahoma Center for the Advancement of Science and Technology (HR14-160).

\section{References}

1. Mori S, Ueda T, Kuratsu S, Hosono N, Izawa K, Uchida A. Int J Cancer. 1995; 61:148. [PubMed: 7535752]

2. Grimer RJ. Lancet Oncol. 2005; 6:85. [PubMed: 15683817]

3. Kansara M, Teng MW, Smyth MJ, Thomas DM. Nat Rev Cancer. 2014; 14:722. [PubMed: 25319867]

4. Yamagishi K, Onuma K, Suzuki T, Okada F, Tagami J, Otsuki M, Senawangse P. Nature. 2005; 433:819. [PubMed: 15729330]

5. Laurencin D, Almora-Barrios N, de Leeuw NH, Gervais C, Bonhomme C, Mauri F, Chrzanowski W, Knowles JC, Newport RJ, Wong A, Gan Z, Smith ME. Biomaterials. 2011; 32:1826. [PubMed: 21144581]

6. Li Y, Li Q, Zhu S, Luo E, Li J, Feng G, Liao Y, Hu J. Biomaterials. 2010; 31:9006. [PubMed: 20800275]

7. Thian ES, Huang J, Best SM, Barber ZH, Brooks RA, Rushton N, Bonfield W. Biomaterials. 2006; 27:2692. [PubMed: 16423389]

8. Low HR, Avdeev M, Ramesh K, White TJ. Adv Mater. 2012; 24:4175. [PubMed: 22714569] 
9. Loscalzo J. N Engl J Med. 2014; 370:1756. [PubMed: 24785212]

10. Rayman MP. Lancet. 2012; 379:1256. [PubMed: 22381456]

11. Cao JJ, Gregoire BR, Zeng H. J Nutr. 2012; 142:1526. [PubMed: 22739365]

12. Fang W, Han A, Bi X, Xiong B, Yang W. Int J Cancer. 2010; 127:32. [PubMed: 19904745]

13. Dong H, Ying T, Li T, Cao T, Wang J, Yuan J, Feng E, Han B, Hua F, Yang Y, Yuan J, Wang H, Xu C. J Cell Biochem. 2006; 98:1495. [PubMed: 16552729]

14. Weekley CM, Aitken JB, Vogt S, Finney LA, Paterson DJ, de Jonge MD, Howard DL, Witting PK, Musgrave IF, Harris HH. J Am Chem Soc. 2011; 133:18272. [PubMed: 21957893]

15. Cao B, Yang M, Zhu Y, Qu X, Mao C. Advanced Materials. 2014; 26:4627-4631. [PubMed: 24890678]

16. Qiu P, Qu X, Brackett DJ, Lerner MR, Li D, Mao C. Advanced Materials. 2013; 25:2492-2496. [PubMed: 23450784]

17. Gandra N, Abbineni G, Qu X, Huai Y, Wang L, Mao C. Small. 2013; 9:215-221. [PubMed: 23047655]

18. Janardhanan SK, Narayan S, Abbineni G, Hayhurst A, Mao C. Molecular Cancer Therapeutics. 2010; 9:2524-2535. [PubMed: 20807781]

19. Abbineni G, Modali S, Safiejko-Mroczka B, Petrenko VA, Mao C. Molecular Pharmaceutics. 2010; 7:1629-1642. [PubMed: 20735141]

20. Wang Y, Ma J, Zhou L, Chen J, Liu Y, Qiu Z, Zhang S. Interface Focus. 2012; 2:378. [PubMed: 23741613]

21. Klein CP, de Blieck-Hogervorst JM, Wolke JG, de Groot K. Biomaterials. 1990; 11:509. [PubMed: 2242400]

22. Guan L, Han B, Li Z, Hua F, Huang F, Wei W, Yang Y, Xu C. Apoptosis. 2009; 14:218. [PubMed: 19130236]

23. Han B, Ren Y, Guan L, Wei W, Hua F, Yang Y, Yang T, Cao T, Dong H, Pan H, Xu C. Oncol Res. 2009; 17:373. [PubMed: 19544974]

24. Wu S, Bao Y, Ma D, Zi Y, Yang C, Yang M, Xing M, Yang W. Int J Mol Med. 2014; 34:1175. [PubMed: 25198010]

25. Babenko GA, Pogribnyi IP, Mashchakevich. Eksp Onkol. 1986; 8:31. [PubMed: 3757881]

26. Kuklinski B, Zimmermann T, Schweder R. Med Klin (Munich). 1995; 90(Suppl 1):36. [PubMed: 7715583]

27. Vinogradova LF, Kharlitskaia EV, Mirzoian Zh A. Farmakol Toksikol. 1989; 52:53. [PubMed: 2540027]

28. Simonet WS, Lacey DL, Dunstan CR, Kelley M, Chang MS, Luthy R, Nguyen HQ, Wooden S, Bennett L, Boone T, Shimamoto G, DeRose M, Elliott R, Colombero A, Tan HL, Trail G, Sullivan J, Davy E, Bucay N, Renshaw-Gegg L, Hughes TM, Hill D, Pattison W, Campbell P, Sander S, Van G, Tarpley J, Derby P, Lee R, Boyle WJ. Cell. 1997; 89:309. [PubMed: 9108485]

29. Jain A, Betancur M, Patel GD, Valmikinathan CM, Mukhatyar VJ, Vakharia A, Pai SB, Brahma B, MacDonald TJ, Bellamkonda RV. Nat Mater. 2014; 13:308. [PubMed: 24531400]

30. Pollack A, DeSilvio M, Khor LY, Li R, Al-Saleem TI, Hammond ME, Venkatesan V, Lawton CA, Roach M 3rd, Shipley WU, Hanks GE, Sandler HM. J Clin Oncol. 2004; 22:2133. [PubMed: 15169799]

31. Valastyan S, Weinberg RA. Cell. 2011; 147:275. [PubMed: 22000009]

32. Tay CY, Cai P, Setyawati MI, Fang W, Tan LP, Hong CHL, Chen X, Leong DT. Nano Lett. 2014; 14:83-88. [PubMed: 24313755]

33. Tay CY, Setyawati MI, Xie J, Parak WJ, Leong DT. Advanced Functional Materials. 2014; 24:5936-5955. 

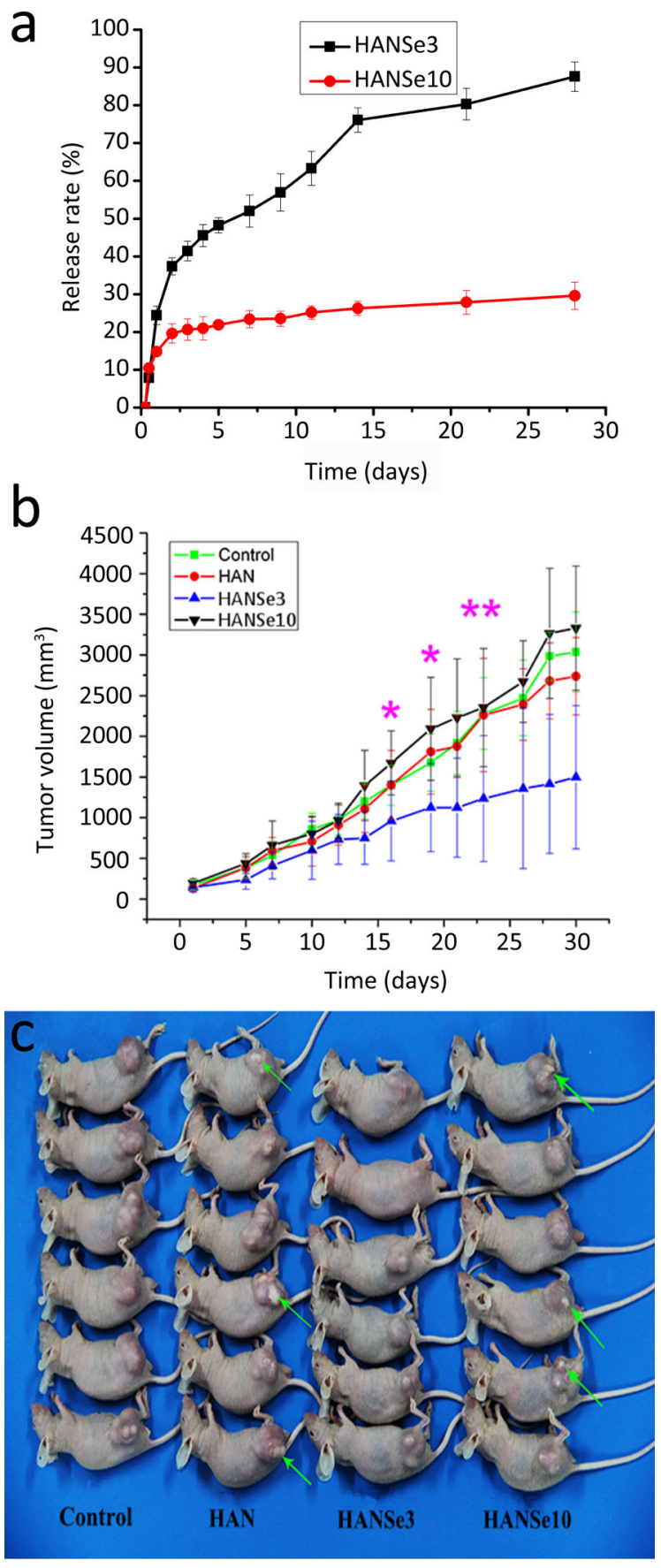

Figure 1.

Cumulative release of selenite ions and therapeutic effect of HANSe treatment on aggressive osteosarcoma. a) HANSe3 exhibits a sustained release profile compared to HANSe10. All experiments are repeated at least three times. b) Plot of tumor volume versus time. Mice bearing osteosarcoma are euthanized at each predetermined time point, and no mice die from tumor. Data are presented as mean tumor volume \pm standard deviation $(n=3)$. Tumors in the HANSe3 group are significantly smaller than all other groups from day 15 to day 23 (* indicates $\mathrm{p}<0.05$ for HANSe 3 and $* *$ indicates $\mathrm{p}<0.01$ for HANSe3, versus no treatment 
control, HANSe10, and HAN groups by SPSS with Tukey's multiple comparison tests). c) Gross view of representative tumor-bearing mice after treatments for 30 days. Green arrows highlight the remaining dense materials. 


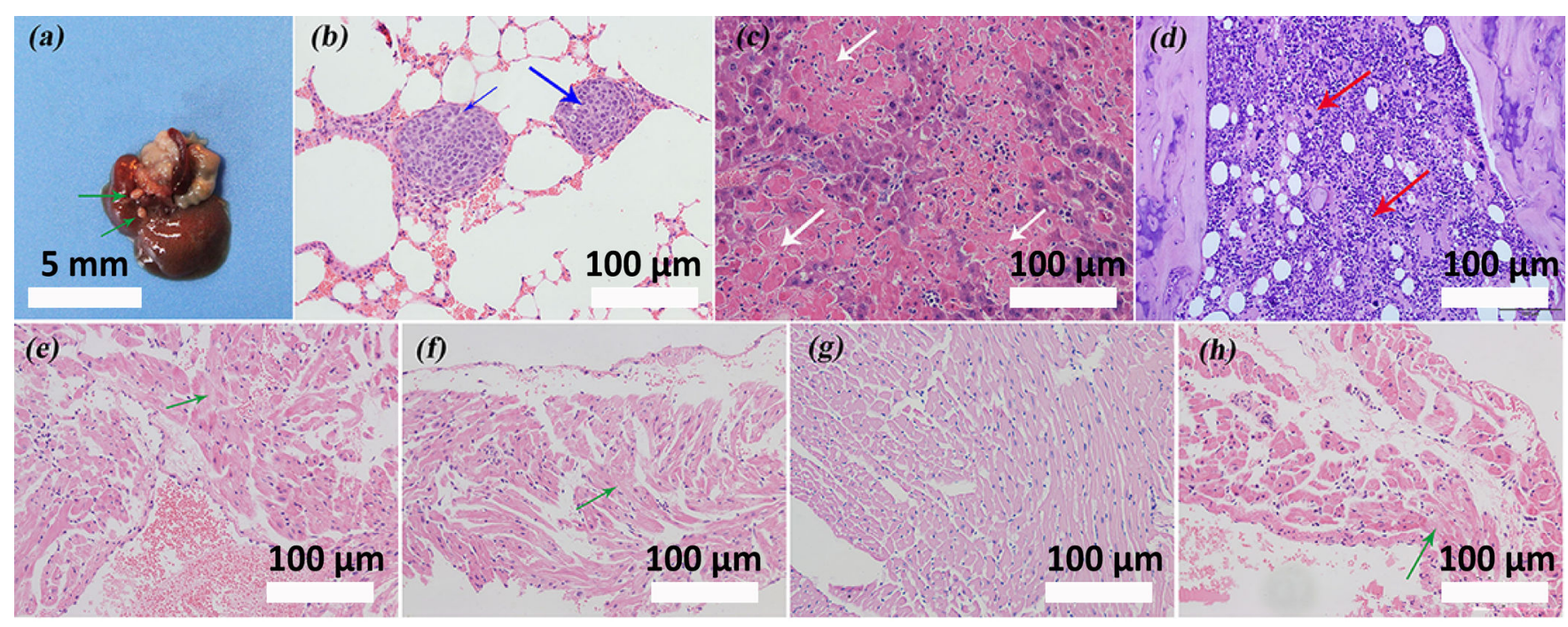

Figure 2.

HANSe inhibits tumor metastasis and protects cardiac tissue from malignant infiltration. a) Representative liver image with visible metastatic tumor from mice in control group. Green arrows indicate the metastatic osteosarcomas. b) Hematoxylin-eosin (H\&E) staining shows lung metastasis of the tumor in control group, as highlighted by blue arrows. The deep-dyed big nuclei reveal that the tumor cells are in a typical mitotic phase. c) H\&E staining for liver tissue slides in control group demonstrates the hepatocytes necrosis (white arrows) and monocytes infiltration. d) The presence of giant cells and lymphocytes (red arrows) visualized by H\&E staining reveals that an inflammation reaction in bone marrow is induced in control group. (e-h) H\&E staining of cardiac tissue acquired after treatments for 30 days with saline, HAN, HANSe3 and HANSe10. e) Prominent degenerative changes of cardiac muscle are evidenced in saline group. g) HANSe3 effectively protects cardiac muscle from degeneration. (f \& h) Neither HAN (f) nor HANSe10 (h) improves the degenerative changes. 

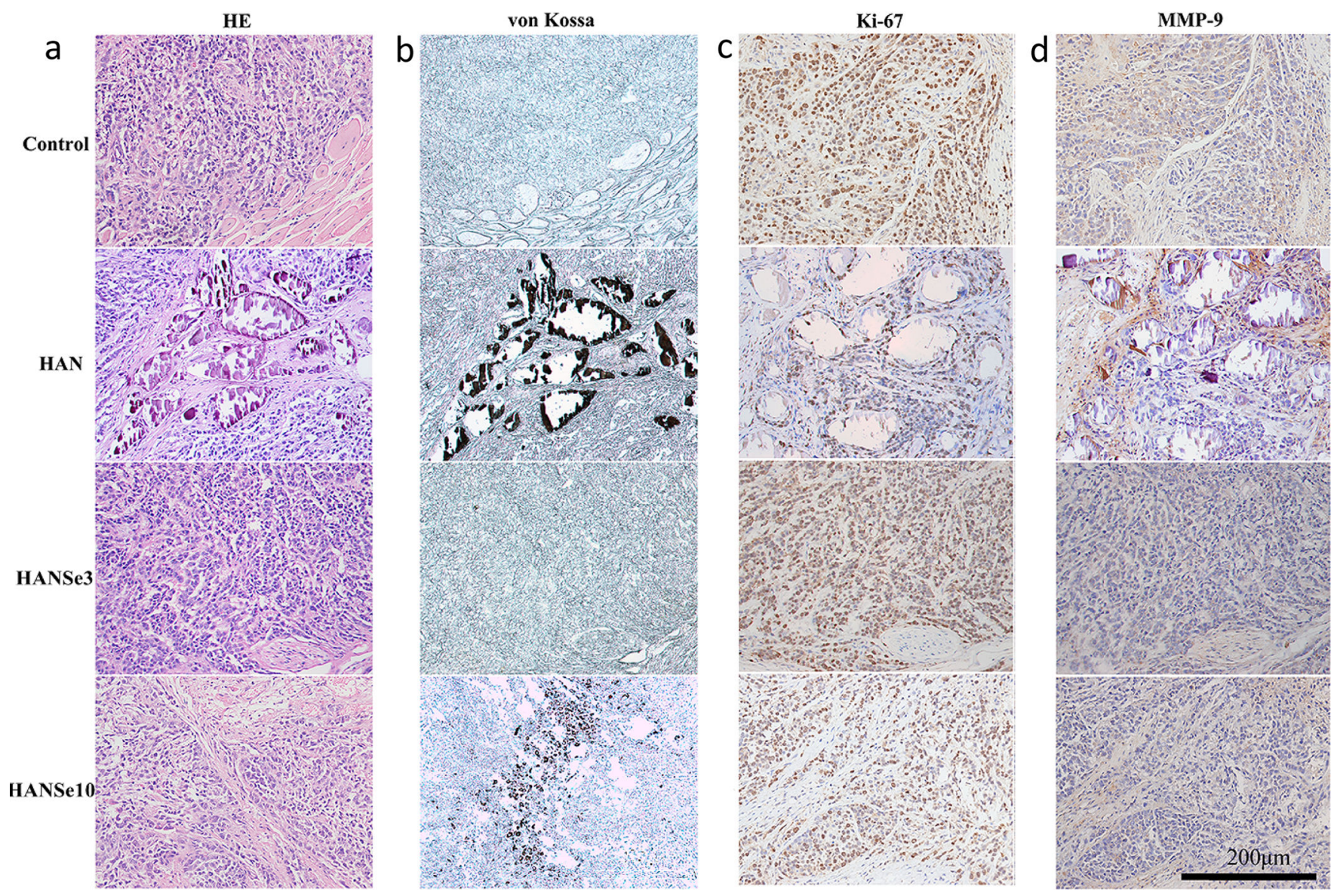

Figure 3.

Tumor necrosis induced by HANSe3 through suppressing MMP-9 is associated with in vivo biodegradation. a) H\&E staining of osteosarcoma tissue from mice with treatments for 30 days. Tumor cells are found infringing into adjacent muscular layer in control and HANSe10 group. The tumor tissue in HANSe3 group is separated into minor tumors by fibrous tissues, exhibiting a necrosis phenotype. b) Von Kossa staining of osteosarcoma tissue indicates the presence of residual materials. HAN is not degraded and the particles aggregate to form granules that are encapsulated by fibrous tissues. The negative staining for HANSe3 group indicates that HANSe3 nanoparticles have been completely degraded. The expressions of Ki-67 (a maker protein for malignant proliferation), and MMP-9 (a metalloproteinase responsible for extracellular matrix degradation and tumor invasion) were evaluated by immunohistochemical staining (c-d). There is no difference for Ki-67 expression between groups (c), indicating that tumor cell proliferation is not effected by HANSe. d) HANSe3 significantly decreased MMP-9 expression, suggesting that HANSe3 may inhibit osteosarcoma by suppressing tumor invasion instead of cell proliferation. 

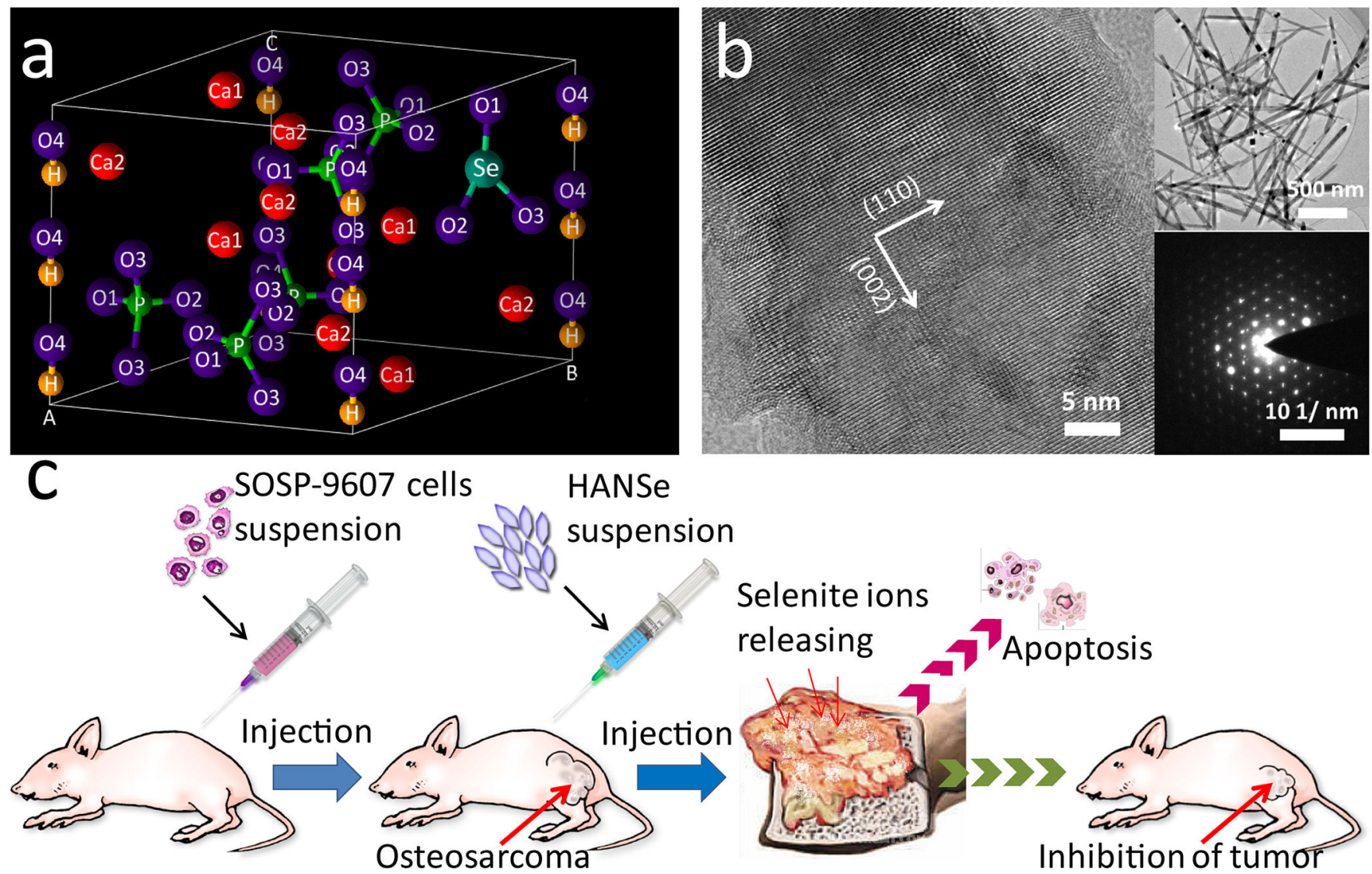

Scheme 1.

Illustration of HANSe in treating osteosarcoma. a) Crystal lattice of HANSe showing the substitution of phosphate ions with selenite ions. b) High resolution transmission electron microscope (HR-TEM) images of HANSe. Insets are morphology (top) and selected area electron diffraction (SAED, bottom) of the HANSe nanoparticles. c) General concept of osteosarcoma treatment with HANSe. Nude mice model bearing primary tumor is constructed by orthotopic intra-femur injection of SOSP-9607 cells of human origin. HANSe nanoparticles are in-situ injected for the evaluation of their anti-tumor efficiency. 